\title{
Disturbances of Solar Eruption From Active Region AR1613
}

\author{
Z. S. Hamidi ${ }^{1, \star}$, N. N. M. Shariff ${ }^{2}$, C. Monstein ${ }^{3}$ \\ ${ }^{1}$ School of Physics and Material Sciences, Faculty of Sciences, MARA University of Technology, \\ 40450, Shah Alam, Selangor, Malaysia \\ ${ }^{2}$ Academy of Contemporary Islamic Studies (ACIS), MARA University of Technology, \\ 40450, Shah Alam, Selangor, Malaysia \\ ${ }^{3}$ Institute of Astronomy, Wolfgang-Pauli-Strasse 27, Building HIT, Floor J, \\ $\mathrm{CH}-8093$ Zurich, Switzerland \\ *E-mail address: zetysh@salam.uitm.edu.my
}

\begin{abstract}
The paper describes an investigation of the solar radio bursts of spectral type III due to disturbances of the active region AR 1613. A solar flare occurred on 2012 November 15, between 2:00 UT to 3:30 UT. The sequence images from a burst from our site revealed that although the solar flare is considered moderate, it is still possible to obtain the solar burst type III in a single and group forms within one and half hour. It can easily produce misleading results in terms of nonthermal electron density and magnetic field strength. The burst is originated in the same active region of the solar corona. The C-6 level enhancement was detected in GOES 1.8 a soft X-ray. Based on the results, we suggest that radio wave source motion manifests the displacement of particle sites caused by plasma eruptions. Time variability in the emission may due to the changes in the electron density. The group and individual solar burst type III can be related to the distance travelled before an electron beam becomes unstable to Langmuir waves. In conclusion, the interactions non-thermal electron and magnetic trapping can influence the transporting of electrons and this is still a subject of interest of intense investigation.
\end{abstract}

Keywords: Solar radio emission; solar burst type III; e-CALLISTO; solar flare; Active Region AR1613

\section{INTRODUCTION}

It has been a long thought that the disturbance of the solar eruption initiated by active region with a strong magnetic field. The repeat heating by coronal and chromospheric material will expand to the interplanetary medium and Earth's atmosphere which can be detected in radio region. Normally this solar eruption is synonymous with solar radio burst type III. In principle, the radio observations specifically in low region provide an indication of Sun activities such as Coronal Mass Ejections (CMEs), solar flare, evolution of sunspots and others unpredictable phenomena [1]. It plays an important role in understanding the mechanism of energy release, plasma heating, the particle acceleration and transfer in magnetized plasmas. In fact, they originate in the same layers of the solar atmosphere in which geo-effective disturbances probably originate the layers where energy is released in 
solar flares, where energetic particles are accelerated and where Coronal Mass Ejections (CMEs) are launched [2,3]. Therefore, the dynamical process during the burst of flares or CMEs events can be traced from this observation [4,5]. The solar radio bursts type III has a high probability of being followed by geomagnetic disturbances [6]. It forms in a fast drift formation and can last from hours to a few days in the region of $\mathrm{KHz}$ till $\mathrm{GHz}$ [7]. As the energetic electrons from the solar flare move outward from the corona, they stimulate oscillations at the electron plasma frequency, $\mathrm{f}_{\mathrm{p}}$, which is a characteristic oscillation frequency of the plasma at the atmosphere of the Sun. There are three low-frequency variants of type III burst that originate in the interplanetary (IP) medium [8]: (i) isolated type III bursts from flare -scale energy releases, (ii) complex type III bursts during CMEs, and (iii) type III storms. Determination of solar burst type III could be interpreted as a very fast outward movement of the disturbance through the solar corona with could exceed from $3 \times 10^{4}$ to $10^{5} \mathrm{~km} / \mathrm{sec}$. This velocity represents one-third velocity of light. The electrons in this type are accelerated to energies of at least $10^{4}$ to $10^{5} \mathrm{eV}$. Previous study also shown that this type of burst extends out to $1 \mathrm{AU}$ [9] with more than $20 \mathrm{keV}$ electrons [10]. Therefore, this type is used as tracers of magnetic field structures. At very low frequencies $(\sim 1 \mathrm{MHz})$, several thousand of bursts can be emitted from an active region during one complete solar rotation [11]. An important question concerning the origin of this burst is how they correlate with the mildly relativistic electrons and Langmuir waves produced from the electrons. It should be noted that observations show that Langmuir waves associated with solar type III radio bursts are highly localized [12]. One fundamental theory, it is believed is that Landau resonance with the unstable electron beam is responsible generates Langmuir waves, which are thought to undergo nonlinear wave-wave interactions that produce electromagnetic emissions at the local electron plasma frequency $\left(\mathrm{f}_{\mathrm{pe}}\right)$ and its second harmonic $\left(2 \mathrm{f}_{\mathrm{pe}}\right)$ [13-15].

\section{EXPERIMENTAL SETUP AND METHODOLOGY}

The radio astronomy in Malaysia has just started in a few years ago since 2006 [16]. Considering the observational facts, we used the Compound Astronomical Low-cost Lowfrequency Instrument for Spectroscopy and Transportable Observatory (CALLISTO) system which is connected to the Log Periodic Dipole Antenna (LPDA) [17,18]. The LPDA is constructed in February 2012 [19]. The system is located at the National Space Centre (ANGKASA), Selangor located at $\left(3.0833333^{\circ} \mathrm{N} 101.5333333^{\circ} \mathrm{E}\right)$ with minimum Radio Frequency Interference (RFI) noise level, with an average - (85-100) dBm [17,20,21]. Until now, we have construct and modified the LPDA in order to obtain a better data of solar burst [22]. Although the main purpose of the instrument is to provide imaging data, in order to study a large number of bursts, we restrict ourselves to total power data without spatial resolution. Basically, a LPDA that can cover the range of frequency from $45-870 \mathrm{MHz}$ is connected to the CALLISTO spectrometer [23]. Nevertheless, in order to minimize the noise level, we focus only in the region of $150 \mathrm{MHz}$ till $400 \mathrm{MHz}$ [24,25]. We have to note that it is difficult to measure the duration of the burst more than $400 \mathrm{MHz}$ seems the region has a moderate noise [26,27]. It also has a moderate population density of people and technology applications $[28,29]$. This region also has been evaluated and compared with the observatory in Thailand [30]. The distribution data radio flux density in burst versus the frequency range of the spectral peak and intensity level has been collected daily starting from 11:30 UT till 23.30 UT [31,32]. Each burst consists of 15 minutes of dynamic spectrum with 0.25 second time resolution [33]. One of the apparent disadvantages of the spectral expansion and the limited averaging 
procedure is that this data can be only automatically saved on a daily basis only. In principle, a regular practice to distinguish metric solar radio burst signals is to record the digital dynamical spectra, extract sequences of single frequency events with limited discrete length and to determine quantitative characteristics on the basis of these observations [34-48].

\section{RESULTS AND ANALYSIS}

In the present work, we considered times profiles of solar radio burst type III from 150 $400 \mathrm{MHz}$. The Active Region 1613, located at the South - West of the Sun, was recorded by the Geostationary Operational Environmental Satellites (GOES). During the impulsive phase, six Active Region at the center of the Sun (i) 1610, (ii) 1611, (iii) 1612, (iv) 1614, (v) 1615 and (iv) 1616 an be observed directly. These Active Region seems to be passive within this few days. The significant solar burst variations happened starting from 1:57 UT. The time profiles of the from 2:45 UT - 3:00 UT is sometime complex contain more that one than one type of burst. The increase of radio burst is accompanied by a decrease in distance between source of seven active regions. These estimates are rather subjective and need elaboration For this study, we also used the data from the space weather website. Detailed is the condition of the Sun and the percentage of solar flare an M and X class on 15th November 2012 during this event is listed in Table 1 and Table 2.

Table 1. Current condition of the Sun (Credited to Space Weather).

\begin{tabular}{|c|c|}
\hline Parameter & Value \\
\hline Solar wind speed & $403.5 \mathrm{~km} / \mathrm{sec}$ \\
\hline Density & $1.7 \mathrm{protons} / \mathrm{cm}^{3}$ \\
\hline Sunspot number & 126 \\
\hline $10.7 \mathrm{~cm}$ flux & $146 \mathrm{sfu}$ \\
\hline 6-hr max & $\mathrm{C} 1$ \\
\hline $24-\mathrm{hr}$ & $\mathrm{C} 6$ \\
\hline
\end{tabular}

Table 2. The percentage of solar flare an $M$ and $X$ class on $15^{\text {th }}$ November 2012 (Credited to Space Weather).

\begin{tabular}{|c|c|c|}
\hline Flare & $0-24$ hours & $24-48$ hours \\
\hline Class M & $40 \%$ & $40 \%$ \\
\hline Class X & $5 \%$ & $5 \%$ \\
\hline
\end{tabular}




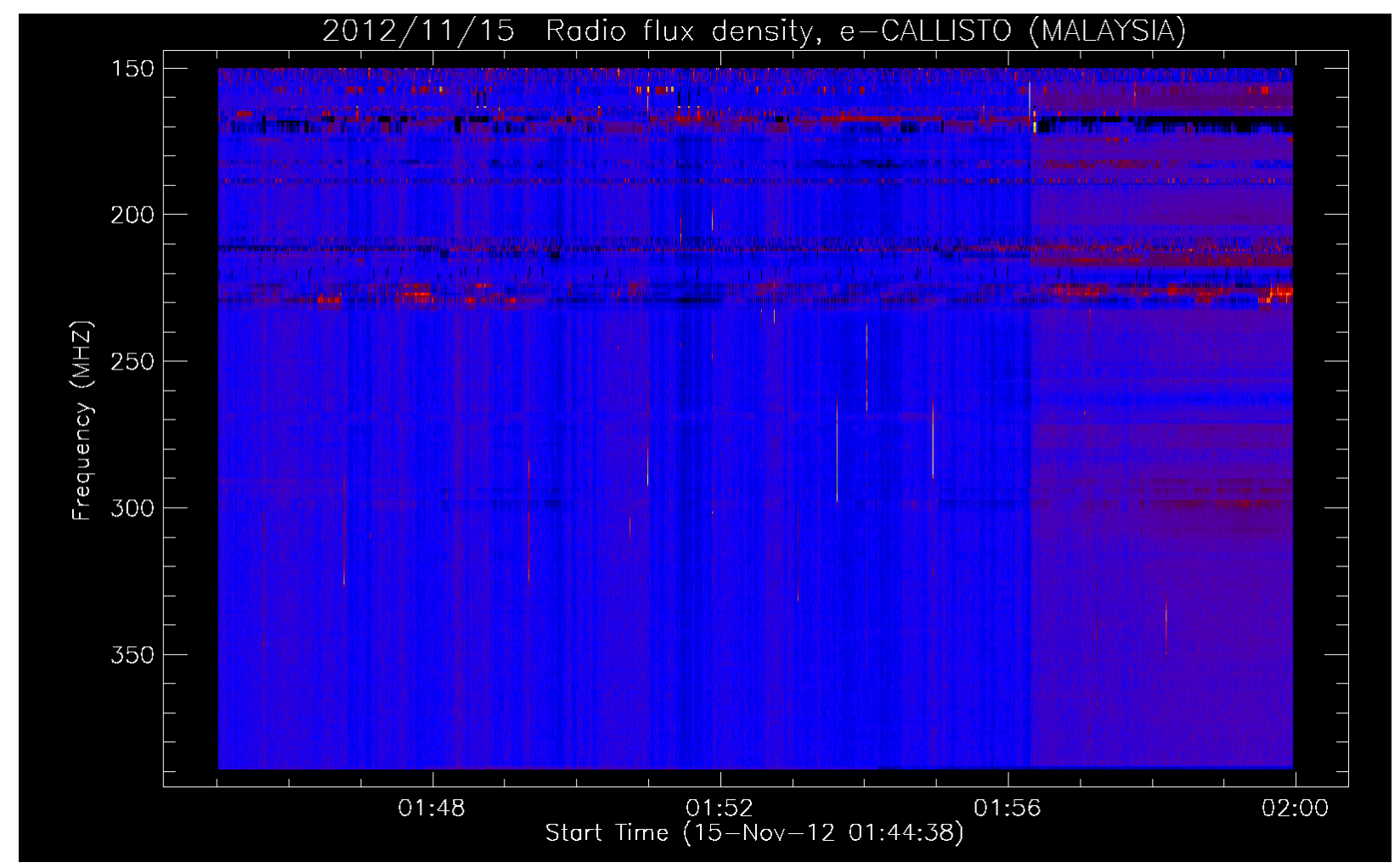

Figure 1. Time profile of the radio burst type III associated with a C-6 class solar flare on 15th November 2012 from 1:45 UT- 2:00 UT at the National Space Centre, Banting Selangor.

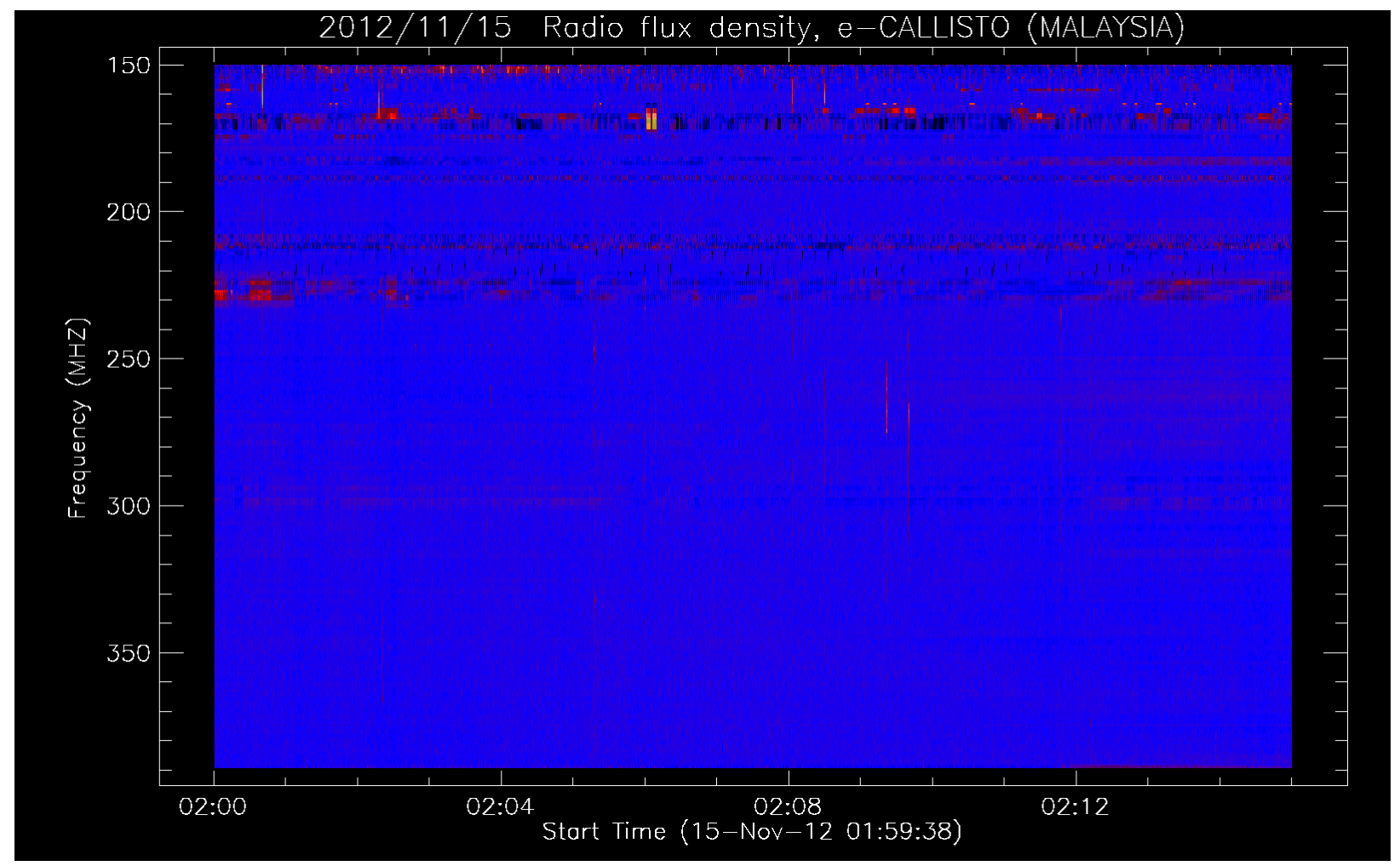

Figure 2. Time profile of the radio burst type III associated with a C-6 class solar flare on 15 th November 2012 from 2:00 UT- 2:15 UT at the National Space Centre, Banting Selangor. 


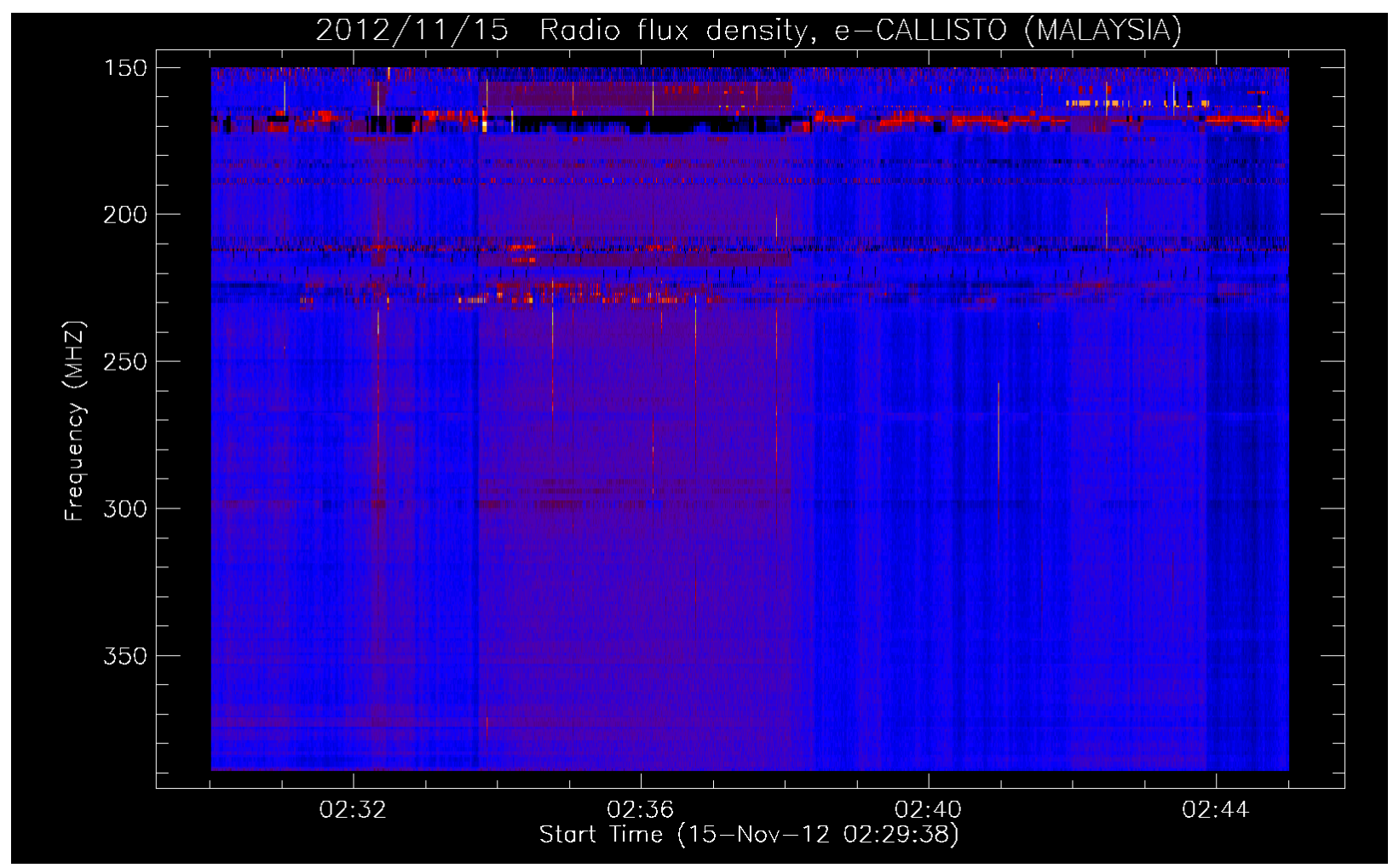

Figure 3. Time profile of the radio burst type III associated with a C-6 class solar flare on 15 th November 2012 from 2:15 UT- 2:30 UT at the National Space Centre, Banting Selangor.

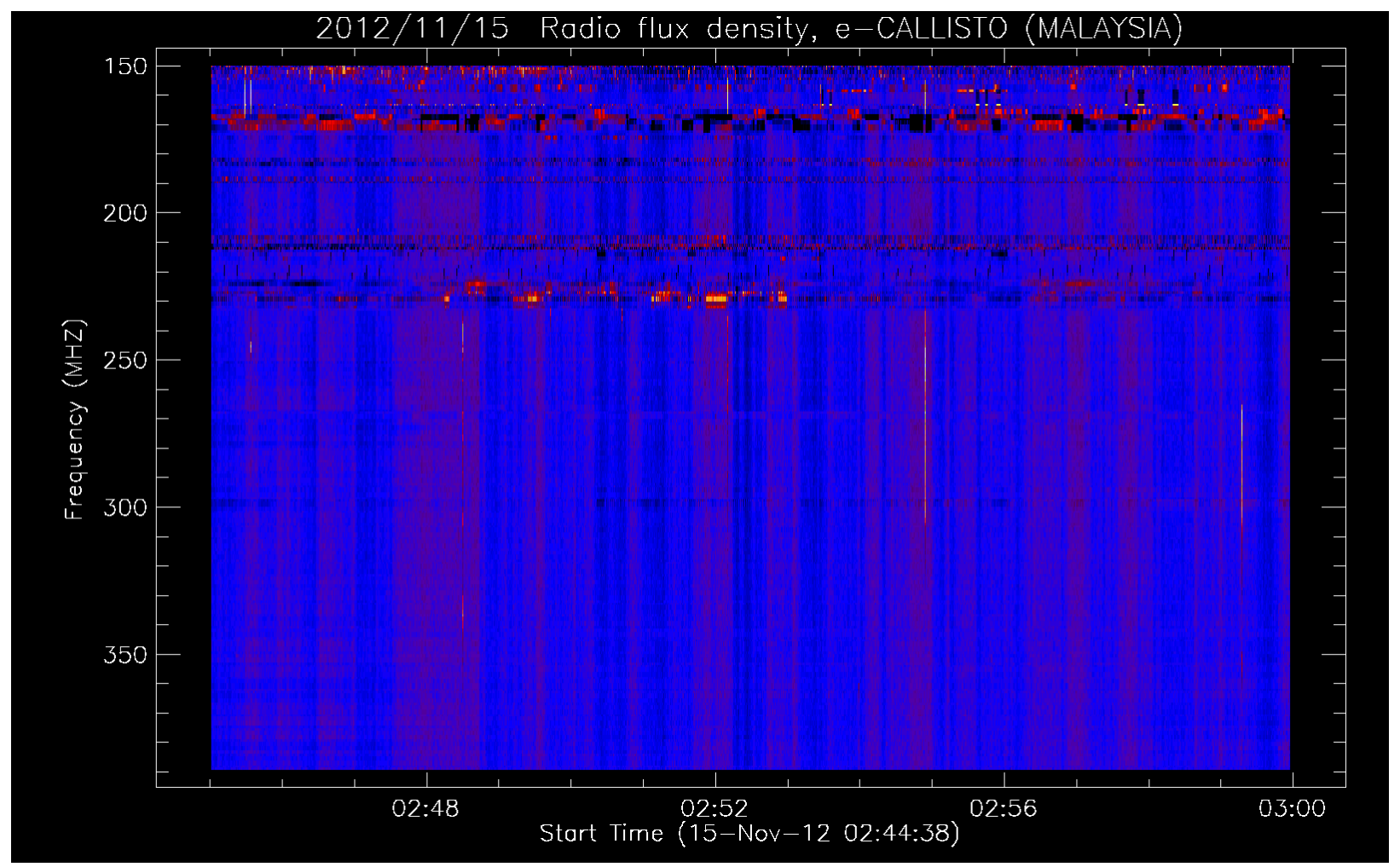

Figure 4. Time profile of the radio burst type III associated with a C-6 class solar flare on 15 th November 2012 from 2:30 UT- 2:45 UT at the National Space Centre, Banting Selangor. 


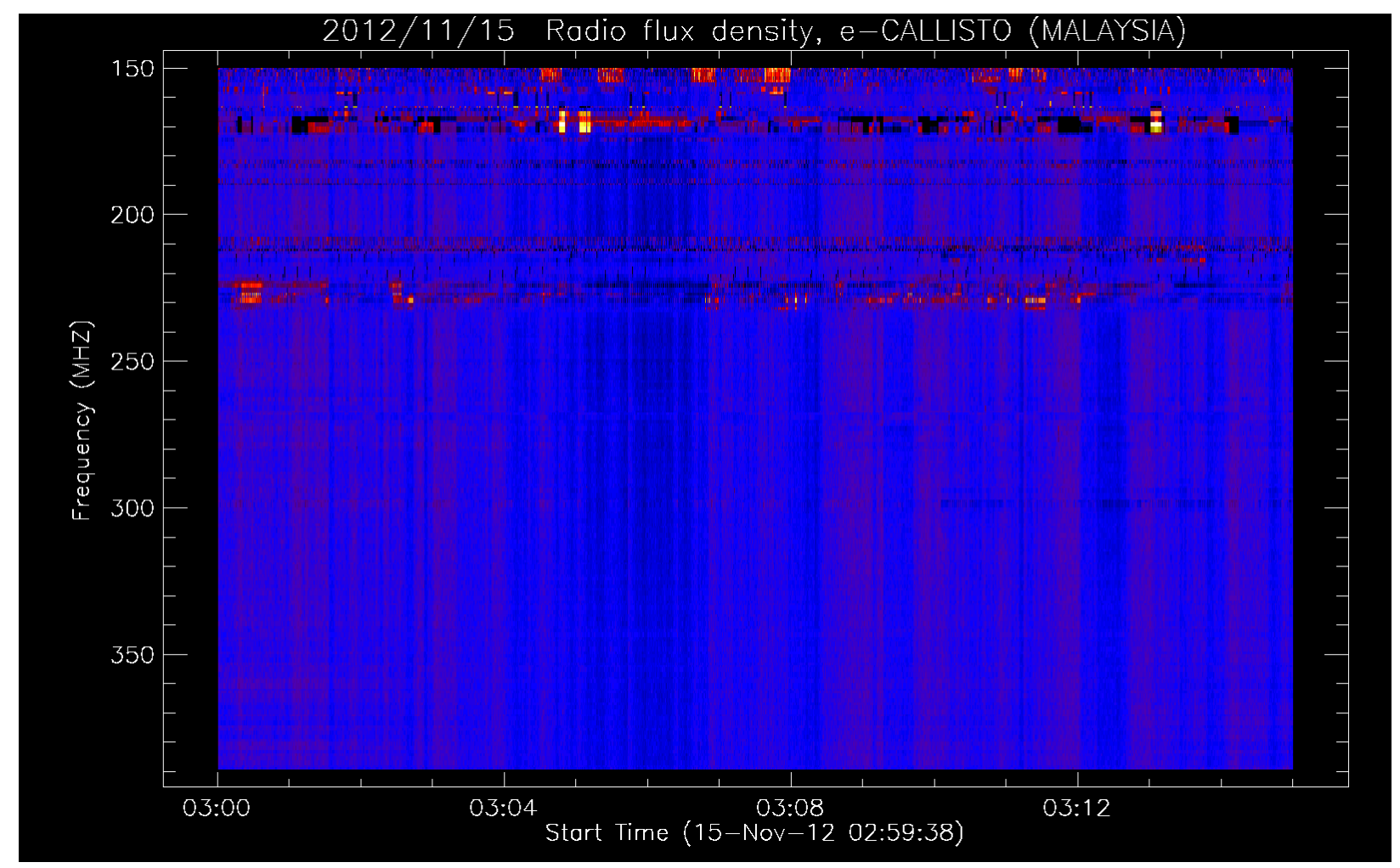

Figure 5. Time profile of the radio burst type III associated with a C-6 class solar flare on 15 th November 2012 from 3:00 UT- 3:15 UT at the National Space Centre, Banting Selangor.

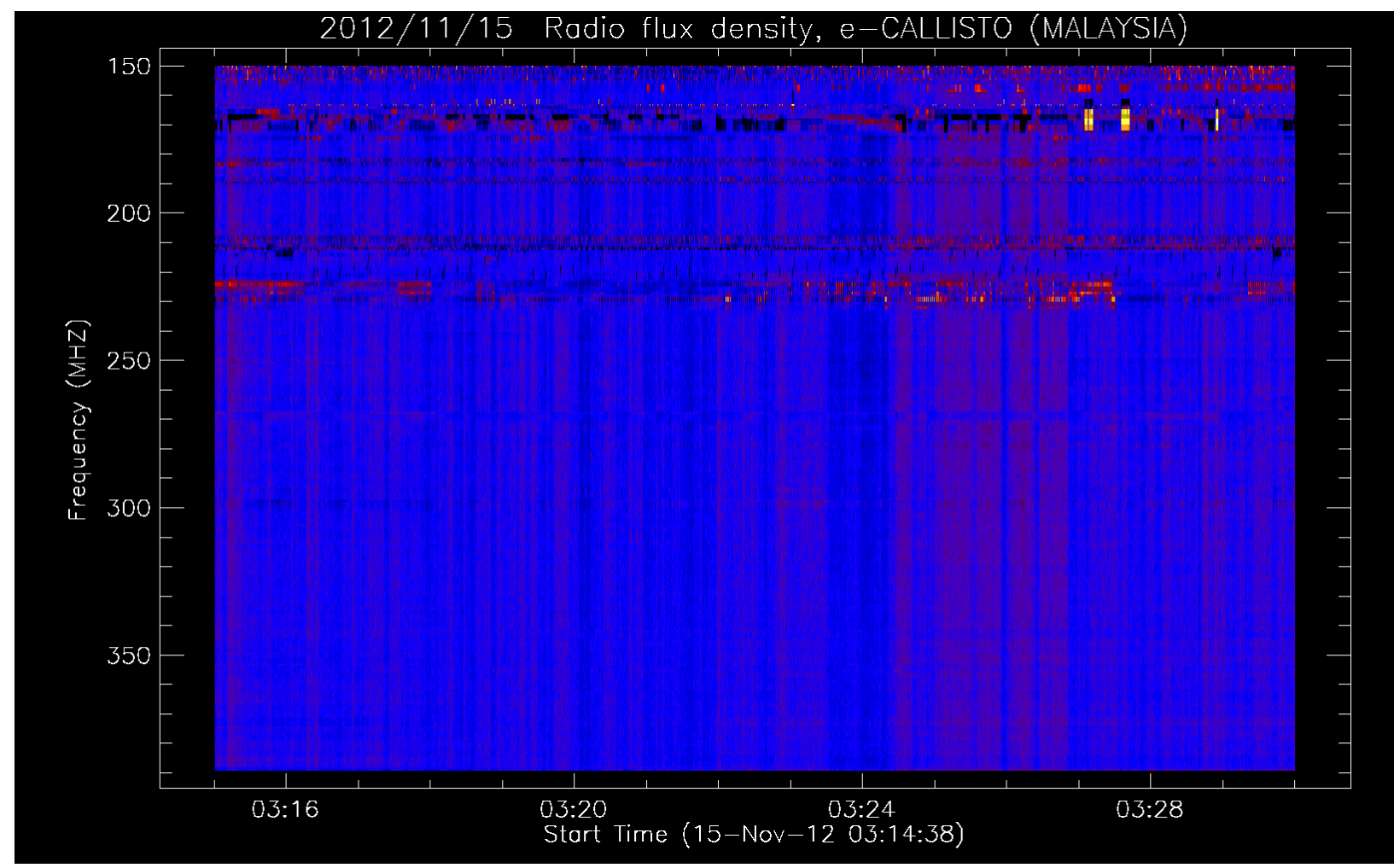

Figure 6. Time profile of the radio burst type III associated with a C-6 class solar flare on 15 th November 2012 from 3:15 UT- 3:30 UT at the National Space Centre, Banting Selangor. 
The sequence images from a burst from our site revealed that although the solar flare is considered moderate, it is still possible to obtain the solar burst type III in a single and group forms within one and half hour. Such as the short duration and small flare loop, and latter case is more plausible. The burst is originated in the same active region of the solar corona in which geo-effective disturbance probably initiates. Based on the observations, strong bursts that caused by extraordinary solar flares due to magnetic reconnection effect potentially induced in the near-Earth magneto tail. It can easily produce misleading results in terms of non-thermal electron density and magnetic field strength. Theoretically, time variability in the emission may due to the changes in the electron density. The tenuous plasma in that region is then accelerated down magnetic field lines into the Polar Regions, striking Earth's atmosphere and exciting nitrogen and oxygen atoms as well as the other atoms present in our atmosphere. These properties indicate that emission from numerous high energy electrons in a very strong magnetic field suggesting high energy release in the flare formation process.

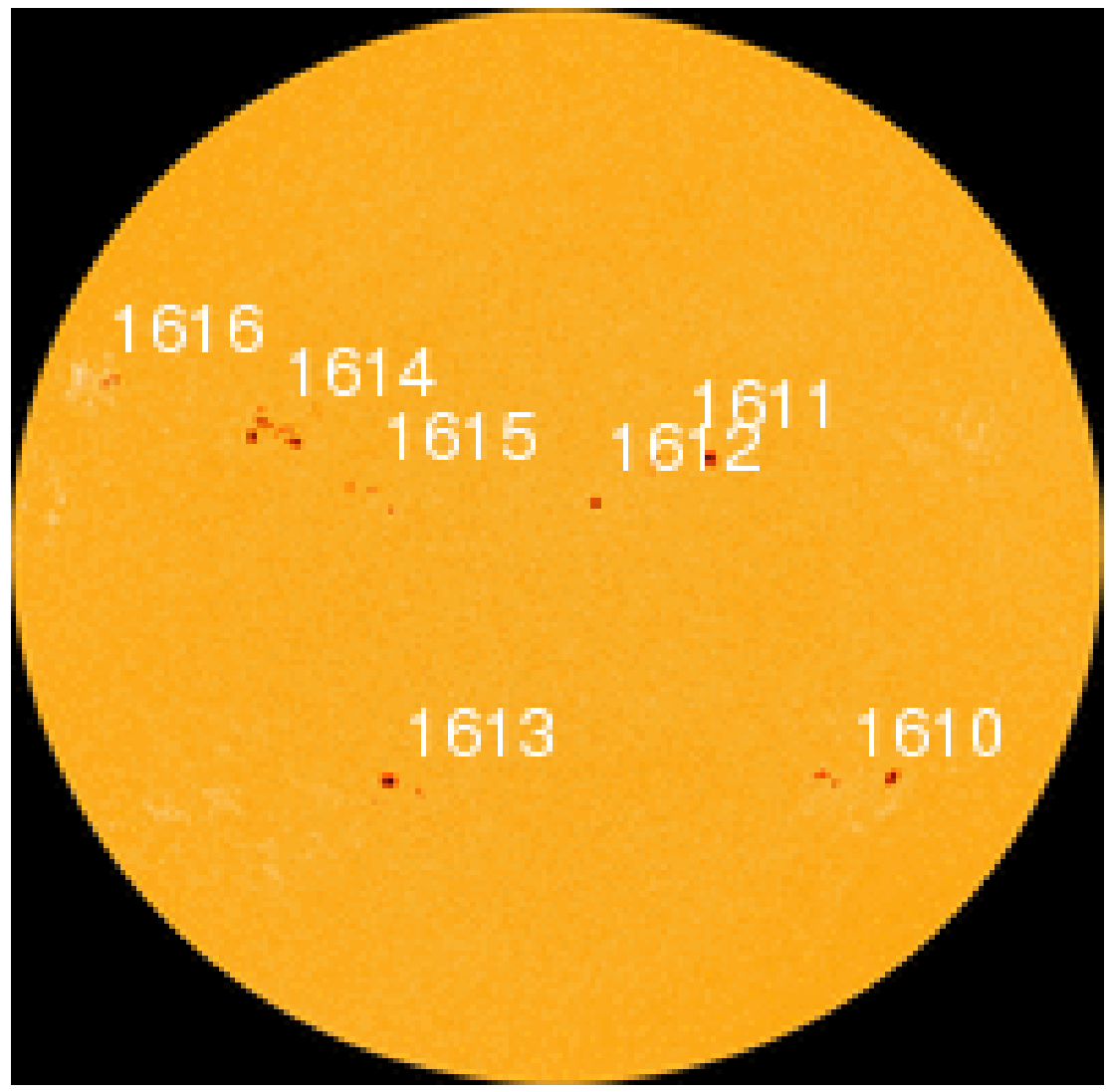

Figure 7. The Active Region 1613 on $15^{\text {th }}$ November 2012.

The combination of radio with the Hard X-ray (HXR) observations can help us to analyze the release of flare energy and acceleration of energetic particles during the pre-phase of the flare. Out of this database, we expected general the procedure, by comparing the GOES data. From our analysis, one possible reason behind the formation of this very complex, long duration of this loop is the magnetic reconnection and disruption of the loops which is observed during flare maximum. Time variations in the emission may due to the changes in the electron density. 


\section{CONCLUDING REMARKS}

The C-6 level enhancement was detected in the GOES 1.8 a soft X-ray. Based on the results, we suggest that radio wave source motion manifest the displacement of particle sites caused by plasma eruptions. To summarize, the burst characteristics of low-frequency solar radio burst type III has been deliberated. A group and individual solar burst type III can be related to the distance travelled before an electron beam becomes unstable to Langmuir waves. In this work, a good agreement was reached and it is believed that Sun's activities are more active to pursuit the solar maximum cycle at the end of this year. In conclusion, the interactions non-thermal electron and magnetic trapping can influence the transporting of electrons and this is still a subject of interest of intense investigation.

\section{ACKNOWLEDGEMENT}

We are grateful to CALLISTO network, STEREO, LASCO,SDO/AIA, NOAA and SWPC make their data available online. This work was partially supported by the FRGS (600 RMI/FRGS 5/3 2012) UiTM grants. Special thanks to the National Space Agency and the National Space Centre for giving us a site to set up this project and support this project. Solar burst monitoring is a project of cooperation between the Institute of Astronomy, ETH Zurich, and FHNW Windisch, Switzerland, MARA University of Technology and University of Malaya. This paper also used NOAA Space Weather Prediction Centre (SWPC) for the sunspot, radio flux and solar flare data for comparison purpose. The research has made use of the National Space Centre Facility and a part of an initiative of the International Space Weather Initiative (ISWI) program.

\section{BIOGRAPHY}

Dr Zety Sharizat Hamidi is currently a lecturer and focused in Solar Astrophysics research specifically in radio astrophysics at the School of Physics and Material Sciences, Faculty of Sciences, MARA University of Technology, 40450, Shah Alam, Selangor, Malaysia. Involve a project under the International Space Weather Initiative (ISWI).

C. Monstein is a senior Engineer at Institute of Astronomy, Wolfgang-Pauli-Strasse 27, Building HIT, Floor J, CH-8093 Zurich, Switzerland and one of the researchers who initiated the CALLISTO system around the world.

Dr Nur Nafhatun Md Shariff is a senior lecturer in Academy of Contemporary Islamic Studies (ACIS), MARA University of Technology, 40450, Shah Alam, Selangor, Malaysia.Her current research is more on sustainability; environmental aspect. She is looking forward for cross-field research, i.e. solar astrophysics, light pollution measurement (mapping) and religious studies.

\section{References}

[1] Z.S. Hamidi, N.N.M. Shariff, F.N.Z. Ulum, Z.Z. Abidin, Z.A. Ibrahim, International Journal of Astronomy 5 (2012) 101-106.

[2] S.M. White, Asian Journal of Physics 16 (2007).

[3] Z.S. Hamidi, N. Anim, N.N.M. Shariff, Z.Z. Abidin, Z.A. Ibrahim, C. Monstein, Dynamical structure of solar radio burst type III as evidence of energy of solar flares, in: R.Shukor (Ed.), PERFIK 2012, American Institute of Physics, Malaysia, 2013, pp. 11-15.

[4] T.S. Bastian, Benz, A.O., Gary, D.E., Annu. Rev. Astron. Astrophys. 36 (1998).

[5] M. Aschwanden, Physics of the Solar Corona, Praxis Publication, Chichester, UK, 2004. 
[6] Z.S.Hamidi, U.F.S.U. Ibrahim, Z.Z. Abidin, Z.A. Ibrahim, N.N.M.Shariff, International Journal of Fundamental Physical Sciences 3 (2013) 20-23.

[7] Z.S.Hamidi, Z. Abidin, Z. Ibrahim, N. Shariff, C. Monstein, Observations of coronal mass ejections (CMEs) at low frequency radio region on 15th April 2012, in: R.Shukor (Ed.), PERFIK 2012, American Institute of Physics, Malaysia, 2013, pp. 5.

[8] N. Gopalswamy, A Global Picture of CMEs in the Inner Heliosphere, in: G. Poletto, Suess, S.T. (Ed.), Astrophysics and Space Science 2004, pp. 201-251.

[9] L.A.a.G. Frank , D.A., Solar Phys. 27 (1972).

[10] H. Alvarez, F.T. Haddock, Lin, R. P., Sol. Phys. 26 (1972).

[11] J. Fainberg, L.G. Evans, Stone R. G., Science 178 (1972).

[12] D.A. Gurnett, R.R. Anderson, Science 194 (1976).

[13] S. Bardwell, M.V. Goldman, ApJ 209 (1976).

[14] D.B. Melrose, Plasma Astrophysics, Gordon and Breach, New York, 1980.

[15] P.A. Robinson, L.H. Cairns, D.A. Gurnett, ApJ 407 (1993).

[16] N. Hashim, Z. Abidin, U. Ibrahim, R. Umar, M. Hassan, Z. Rosli, Z. Hamidi, Z. Ibrahim, Radio Astronomy in Malaysia: Current Status and Outreach Activities, Astronomical Society of the Pacific Conference Series, 2011, pp. 355.

[17] Z.S.Hamidi, N.M.Anim, N. N.S.Hakimi, N.Hamzan, A.Mokhtar, N.Syukri, S.Rohizat, I.Sukma, Z.A. Ibrahim, Z.Z.Abidin, N.N.M.Shariff, C.Monstein, International Journal of Fundamental Physical Sciences 2 (2012) 4.

[18] Z.S. Hamidi, Z. Abidin, Z. Ibrahim, N. Shariff, C. Monstein, International Journal of Engineering Research and Development 3 (2012) 36-39.

[19] Z. Hamidi, Z. Ibrahim, Z. Abidin, M. Maulud, N. Radzin, N. Hamzan, N. Anim, N. Shariff, International Journal of Applied Physics and Mathematics 2 (2012) 140-142.

[20] Z.S. Hamidi, Z. Ibrahim, Z. Abidin, M. Maulud, N. Radzin, N. Hamzan, N. Anim, N. Shariff, International Journal of Applied Physics and Mathematics 2 (2011) 3.

[21] Z.S.Hamidi, N.N.M.Shariff, R.Umar, Malaysia Thailand Journal of Physics 3 (2012) 6.

[22] Z.S. Hamidi, C. Monstein, Z.Z. Abidin, Z.A. Ibrahim, N.N.M. Shariff, International Journal of Engineering Research and Development 3 (2012) 36-39.

[23] Z. Hamidi, N. Shariff, C. Monstein, W.W. Zulkifli, M. Ibrahim, N. Arifin, N. Amran, International Letters of Natural Sciences 5 (2014) 10-17.

[24] Z.S.Hamidi, Z. Abidin, Z. Ibrahim, C. Monstein, N. Shariff, International Journal of Fundamental Physical Sciences 2 (2012) 32-34.

[25] Z.S. Hamidi, Z.Z. Abidin, Z.A. Ibrahim, N.N.M. Shariff, U.F.S.U. Ibrahim, R. Umar, Preliminary analysis of investigation Radio Frequency Interference (RFI) profile analysis at Universiti Teknologi MARA, IEEE, 2011, pp. 311-313.

[26] Z. Hamidi, at al., Malaysian Journal of Science and Technology Studies 9 (2013) 15-22.

[27] Z. Hamidi, Z. Abidin, Z. Ibrahim, N. Shariff, K. Basar, S. Viridi, AIP Conference Proceedings-American Institute of Physics 1454 (2012) 43. 
[28] Roslan Umar, Zamri Zainal Abidin, Zainol Abidin Ibrahim, Mohd Saiful Rizal Hassan, Zulfazli Rosli, Z.S.Hamidi, Population density effect on radio frequencies interference (RFI) in radio astronomy, ICPAP 2012, AIP Conference Proceedings, Bandung Indonesia, 2012, pp. 4.

[29] R. Umar, Z.Z. Abidin, Z.A. Ibrahim, M.S.R. Hassan, Z. Rosli, Z.S. Hamidi, AIP Conference Proceedings 1454 (2012) 39.

[30] R. Umar, et al., Middle East Journal of Scientific Research 14 (2013).

[31] Z.S. Hamidi, N. Shariff, Z. Abidin, Z. Ibrahim, C. Monstein, Middle-East Journal of Scientific Research 12 (2012) 6.

[32] Z.S. Hamidi, N.N.M. Shariff, Evaluation of Signal to Noise Ratio (SNR) of Log Periodic Dipole Antenna (LPDA), Business Engineering and Industrial Applications Colloquium 2013, IEEE, Langkawi, Malaysia, 2013, pp. 434-438.

[33] C. Monstein, R. Ramesh, C. Kathiravan, Bull. Astr. Soc. India 35 (2007) 473-480.

[34] Z. S. Hamidi, N. N. M. Shariff, International Letters of Chemistry, Physics and Astronomy 4 (2014) 29-36.

[35] Z. S. Hamidi, N. N. M. Shariff, International Letters of Chemistry, Physics and Astronomy 5 (2014) 32-42.

[36] Z. S. Hamidi, N. N. M. Shariff, International Letters of Chemistry, Physics and Astronomy 5 (2014) 43-49.

[37] Z. S. Hamidi, N. N. M. Shariff, International Letters of Chemistry, Physics and Astronomy 7 (2014) 21-29.

[38] Z. S. Hamidi, N. N. M. Shariff, International Letters of Chemistry, Physics and Astronomy 7 (2014) 30-36.

[39] Z. S. Hamidi, N. N. M. Shariff, C. Monstein, Z. A. Ibrahim, International Letters of Chemistry, Physics and Astronomy 7 (2014) 37-44.

[40] Z. S. Hamidi, et al., International Letters of Chemistry, Physics and Astronomy 8 (2014) 13-19.

[41] Z. S. Hamidi, N. N. M. Shariff, C. Monstein, W. N. A. Wan Zulkifli, M. B. Ibrahim, N. S. Arifin, N. A. Amran, International Letters of Chemistry, Physics and Astronomy 9 (2014) 8-15.

[42] Z. S. Hamidi, N. N. M. Shariff, M. F. Ali, C. Monstein, W. N. A. Wan Zulkifli, M. B. Ibrahim, N. S. Arifin, N. A. Amran, International Letters of Chemistry, Physics and Astronomy 9 (2014) 84-92.

[43] Z. S. Hamidi, N. N. M. Shariff, C. Monstein, International Letters of Chemistry, Physics and Astronomy 10 (2014) 81-90.

[44] Z. S. Hamidi, N. N. M. Shariff, C. Monstein, International Letters of Chemistry, Physics and Astronomy 11(1) (2014) 51-58.

[45] Z. S. Hamidi, N. N. M. Shariff, C. Monstein, International Letters of Chemistry, Physics and Astronomy 11(2) (2014) 135-145.

[46] Z. S. Hamidi, N. N. M. Shariff, C. Monstein, International Letters of Chemistry, Physics and Astronomy 11(2) (2014) 167-176. 
[47] Z. S. Hamidi, C. Monstein, N. N. M. Shariff, International Letters of Chemistry, Physics and Astronomy 11(3) (2014) 243-256.

[48] Z. S. Hamidi, N. N. M. Shariff, C. Monstein, International Letters of Chemistry, Physics and Astronomy 12 (2014) 84-102. 